\title{
Augmented Reality in VET: Benefits of a qualitative and quantitative study for workplace training
}

\author{
Peter Sommerauer \\ Zurich University of Applied Sciences \\ peter.sommerauer@zhaw.ch
}

\begin{abstract}
Augmented Reality $(A R)$ is widely used in various training and learning settings, like schools, universities, and workplaces. The effects of individual AR learning apps on learning performance in formal learning environments have been examined in detail in various studies. However, up to today only few empirical studies have investigated AR's potential for supporting learning at workplaces and for vocational education and training (VET). In this study we target this research gap by using AR applications for Microsoft Hololens and tablet/smartphone to support learning in technically oriented workplace trainings. We conducted an observational field study with 135 professionals from the event technology industry and the results of our qualitative and quantitative data analysis suggest that integrating AR elements into trainings at workplaces has the potential to enable training experiences which can hardly be simulated with traditional media and which are perceived as beneficial for motivation and learning performance.
\end{abstract}

\section{Introduction}

One of the most significant advantages of AR is to enable immersive learning experiences by connecting digital information and physical objects in the real environment [15]. It has been argued that AR learning experiences especially focus on perception and performance; communication, interaction and collaboration; and the development and expansion of critical thinking and problem-solving skills $[5,14,15$, 32]. For example, interactive $A R$ has the ability to support collaboration in face-to-face and remote settings by sharing a common space and having multiple people view, discuss, and interact with 3D models simultaneously $[10,15,35]$.

AR applications can be designed to address special educational needs of students in vocational education and training institutions and support expert learning [23]. The positive impact of computer supported collaborative learning (CSCL), has been shown in many previous studies [13]. To create a compelling design for AR learning applications, the integration of students, teachers, education technology experts, and software developers into a collaborative creation process is beneficial [4]. To measure learning success in such AR environments, process measures and subjective measures have been proposed as meaningful metrics for experiments and other empirical studies [15].

However, the majority of existing studies investigate $\mathrm{AR}$ in learning and training environments with students $[3,5,28,29]$ and focus solely on usability or student motivation. In the context of vocational training, studies that have investigated AR-based learning were mainly interested in the development and application of tools and in aspects related to user interfaces and hardware. These studies also provided insights about how interactive AR supports learning, in particular by providing multiple means of presentation, expression and engagement.

Measurement and evaluation of learning in personalized learning experiences, e.g., considering the acquisition of skills, competencies and critical thinking, is essential for the evolution of the digitization of education [2]. While most studies use valuable metrics that address perceived usefulness, learning, satisfaction, and dimensions of task completion, such as number of tasks completed or correct answers [20, 31], their application design often lacks a solid learning theory foundation [31].

With our study we aim to gain insights into the design and application of interactive AR applications for learning in vocational education and training in the event technology industry and thus contribute to the existing research gap in interactive AR-based VET. Therefore, we follow Billinghurst et al., who argued that interactive AR supports learning and collaboration on real-world tasks and that this is a particularly promising area for future AR studies [10].

Our study is driven by the assumption that VET trainees using AR based learning systems learn with a higher motivation and achieve a fast, measurable learning outcome. Furthermore, the central aim of our 
field study is to investigate the implementation of interactive $\mathrm{AR}$ in a workplace training environment and to evaluate its application with domain experts. More specifically, we want to answer the research question: What benefits and added value do users see in using interactive $\mathrm{AR}$ in workplace training?

The remainder of this study covers the introduction of the related background, followed by the description of the applied research methodology, and the application development. Subsequently, the test setup, the implementation, and the findings are depicted. In the last section, we discuss our findings and limitations and highlight some aspects for future research.

\section{Background}

Many studies compared learning with AR and nonAR applications. They suggest that AR can have a positive impact on learning in terms of, for example, increased content understanding, learning of spatial structures, language associations, long-term memory retention, improved collaboration, and motivation [28, 29]. However, aspects like attention tunneling, usability difficulties, ineffective classroom integration and learner differences have been identified as potential negative impacts of applying AR for teaching and learning $[28,29]$. Hence, an effective integration of $A R$ into teaching and learning implies the ability to create learning experiences that are aligned with general classroom pedagogy and curriculum [29].

AR demonstrated its potential not only in schools, but also at workplaces for technically and processoriented hands-on training. In this context, is has been argued that future interactive AR applications should focus on supporting ubiquitous, informal, and collaborative learning [3]. Interactive and collaborative learning is widely understood as a situation in which one, two or more people learn or attempt to learn something and together [13], either in pairs, small groups, classes, or communities. Mostly, the learning session follows a predefined course, covering the study of course material or performing learning activities such as problem solving. The collaborative aspect in such learning refers furthermore to the kind of interaction in such constructed learning situations, e.g. either introduced face-to-face or mediated by computer-based systems, and included aspects of synchronous or asynchronous interaction and collaboration across time and space [13].

Interaction and collaboration are natural [13] and AR experiences potentially cause improvements in interaction and group collaboration [7, 8, 33], e.g. in mobile learning environments, using shared displays [29] or face-to-face collaboration in the same location to interact with shared $\mathrm{AR}$ content $[7,8,33]$. In this context, new concepts like Tangible AR (TAR) using Tangible User Interface (TUI) were introduced [27]. Furthermore, location-based AR on mobile devices enables trainees to immerse themselves in the learning process and increase their collaboration skills [4].

Various training situations have been identified where a user requires collaboration on a real-world task, e.g. in public management, crisis situations, urban planning, or to support remote maintenance in various industries [10, 27, 29]. Moreover, AR supports remote and co-located activities in unique ways that would otherwise be almost impossible. Hence, AR has the potential to seamlessly integrate multiple users with display devices in multiple contexts, enhancing telepresence [27].

In a direct comparison, AR performs better in collaborative maintenance sessions than traditional phone assistance [18]. Measures used in interactive and collaborative AR experiments were performance time, game scores, object counts, and performance quality [10]. Therefore, the development and evaluation of AR interfaces constitutes a particularly promising area for further research in this direction [10]. Also, the applied data collection methods to evaluate the effect of AR for interaction and collaboration in training situations as in focus groups or conversational analysis needs to be further explored in future research studies [5].

It is worth noting that previous studies also reported constraints for interactive and collaborative AR training experiences in comparison to non-technological settings. Examples include slower task performance and usability issues, which might explain identified disadvantages in interaction and collaboration [29]. For example, collaboration might invite trainees to compete in a training session, which can lead to rushing and skipping over critical training steps [15]. Additionally, interactive and collaborative AR applications require a stable network connectivity to enable collaboration on virtual content, monitoring students' activities, and controlling the learning experience $[29,35]$.

\section{Methodology}

In our research, we followed Nunamaker's multimethodological approach to IS research [24] and the therefrom derived DAGS framework from Adams et al. [1], which both focus on the integration of design science and systems development. Using design science and systems development methods, we built AR prototypes that embodies different learning theories, represents a proof-of-concept, and allows us to collect empirical data from the field. Subsequently, in the spirit of action research, we used the prototypes to intervene into a simulated real-world training setting and evaluate the usefulness, usability, and learning support of the 
prototypes through quantitative (survey) and qualitative methods (participant feedback and observation).

\begin{tabular}{|c|c|}
\hline $\begin{array}{c}1 . \\
\text { Problem } \\
\text { identification } \\
\text { and motivation }\end{array}$ & $\begin{array}{l}\text { Application of AR might } \\
\text { enhance understanding } \\
\text { of simple and complex } \\
\text { tasks and processes } \\
\text { - Implementing } \\
\text { collaboration in AR based } \\
\text { trainings } \\
\text { - Introduce external } \\
\text { references for skills } \\
\text { acquisition } \\
\end{array}$ \\
\hline $\begin{array}{c}2 . \\
\text { Objectives of } \\
\text { a solution }\end{array}$ & $\begin{array}{l}\text { Development of easily } \\
\text { accessible task } \\
\text { visualizations based on a } \\
\text { step by step approach } \\
\text { - Development of training } \\
\text { assessment tool } \\
\text { (checklist) to support } \\
\text { collaboration between } \\
\text { trainer and trainee } \\
\end{array}$ \\
\hline $\begin{array}{c}3 . \\
\text { Design and } \\
\text { development }\end{array}$ & $\begin{array}{l}\text { - Development of an AR } \\
\text { prototype } \\
\text { - Design / redesign } \\
\text { workflow, visualization, } \\
\text { functionality } \\
\end{array}$ \\
\hline $\begin{array}{c}4 . \\
\text { Demonstration }\end{array}$ & $\begin{array}{l}\text { Test the application of the } \\
\text { prototype with experts in } \\
\text { a test setup } \\
\text { - Test the application of the } \\
\text { prototype within a natural } \\
\text { setup }\end{array}$ \\
\hline $\begin{array}{l}5 . \\
\text { Evaluation }\end{array}$ & $\begin{array}{l}\text { - Evaluate prototype with } \\
\text { domain experts } \\
\text { - Perform a use case- } \\
\text { driven criteria-based } \\
\text { quantitative and } \\
\text { qualitative evaluation } \\
\text { - Define implications for } \\
\text { research and practice } \\
\end{array}$ \\
\hline $\begin{array}{c}6 . \\
\text { Communication }\end{array}$ & - Reporting of results \\
\hline
\end{tabular}

Figure 1. Applied DSR process

For the design and development of the prototypes we applied the design science research (DSR) process model following Peffers et al. [26], illustrated in Figure 1. We developed two interactive and collaborative AR-based prototypes, one for tablets/smartphones and one for the Microsoft Hololens. For the app development we identified the learning process and tasks according an existing competence requirements catalogue which was developed in collaboration with industry training experts.
We collaborated with domain experts from the event technology industry in all stages of the development and evaluation process. The app followed a pre-defined storyline and considered the training requirements derived from a catalogue covering competence requirements, which should be implemented in the training session. Furthermore, the design of the apps was based on design elements derived from learning theories. [31].

Figure 2 shows the conceptual setup for the app development. For logging the user data, we implemented so-called experience-statements recorded on a learning record store (LRS), applying the xAPI [21]. For this purpose, we used Learning Locker ${ }^{\circledR}$ and shaped the XAPI statements to log a user's data to fit the requirements of the performance measurement catalogue.

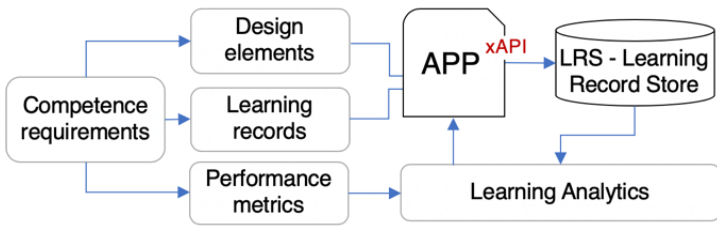

Figure 2. Conceptual setup for app development

Aspects derived from the competence requirements catalogue (Table 1) determine the applied design elements for the app design [31] and the learning records implemented in the apps and define the investigated performance metrics [31], e.g. task performance. The app in practice sends user data to the LRS to provide it for further processing, i.e. for learning analytics and to prepare a feedback for users (e.g. on a dashboard).

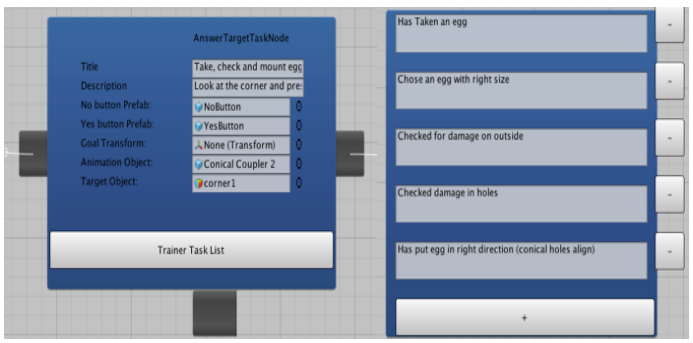

Figure 3. Generic node editor tool

The truss connection application for tablet and smartphone was developed using the Unity3D game engine [19] accompanied by the built-in Vuforia AR and HLAPI (The Multiplayer High-Level API) frameworks. In order to quickly adapt the prototypes to the project requirements, a node editor tool was implemented to generate end applications. This allows the developer to create, edit, and connect nodes (Figure 3 ) - each node 
represents one task that the trainee has to perform (e.g. "Take, check and mount egg on corner 1") which is further subdivided into subtasks (e.g. "Has taken an egg", "Chose an egg with right size", etc).

The application developed for the Microsoft Hololens was built on the basis of the WEKIT framework $^{1}$ which is designed to support processoriented learning tasks. The preparation for the development of the learning application described above supports the creation process of the application. The learning methodology applied in WEKIT is based on three main phases, the (1) capturing and (2) reenacting of an expert performance and (3) reflection.

Table 1. Checklist items related to competences

\begin{tabular}{|c|c|c|}
\hline \multicolumn{2}{|r|}{ Competence reference } & Checklist item description \\
\hline & \multirow{5}{*}{$\begin{array}{l}10.02 \text { Inspect the } \\
\text { technical performance } \\
\text { equipment visually for } \\
\text { damage }\end{array}$} & $\begin{array}{l}\text { Checked for damage on } \\
\text { outside }\end{array}$ \\
\hline & & Checked damage in holes \\
\hline & & $\begin{array}{l}\text { Checked pivot for } \\
\text { damage }\end{array}$ \\
\hline & & Checked if pivot fits \\
\hline & & $\begin{array}{l}\text { Checked if split pen } \\
\text { closes properly }\end{array}$ \\
\hline & \multirow{4}{*}{$\begin{array}{l}10.03 \text { Choose the } \\
\text { right mounting } \\
\text { accessories }\end{array}$} & Has Taken an egg \\
\hline & & $\begin{array}{l}\text { Chose an egg with right } \\
\text { size }\end{array}$ \\
\hline & & Took the right pivot \\
\hline & & Chose correct split pen \\
\hline \multirow{5}{*}{ 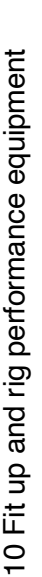 } & $\begin{array}{l}10.04 \text { Choose the } \\
\text { right mounting } \\
\text { methods }\end{array}$ & $\begin{array}{l}\text { Wobbled or hammered } \\
\text { (if needed) }\end{array}$ \\
\hline & \multirow{2}{*}{$\begin{array}{l}10.05 \text { Mount and rig } \\
\text { technical performance } \\
\text { equipment according } \\
\text { to instructions and/or } \\
\text { plans }\end{array}$} & $\begin{array}{l}\text { Has put egg in right } \\
\text { direction (conical holes } \\
\text { align) }\end{array}$ \\
\hline & & $\begin{array}{l}\text { Placed the pivot in right } \\
\text { direction (conical hole) }\end{array}$ \\
\hline & $\begin{array}{l}10.08 \text { Secure } \\
\text { technical performance } \\
\text { equipment and } \\
\text { accessories }\end{array}$ & $\begin{array}{l}\text { Put split pen in hole of } \\
\text { pivot }\end{array}$ \\
\hline & \begin{tabular}{|l}
10.10 Take action if \\
something goes \\
wrong
\end{tabular} & $\begin{array}{l}\text { Disposed damaged pivot } \\
\text { (if needed) }\end{array}$ \\
\hline
\end{tabular}

\section{Test Setup}

Our setup of the field study was built upon the theory for action research to produce relevant research results, primarily in a way that links and interacts with and synergistically influences research and practice [1]. To simulate a realistic workplace environment, we built a $6 \mathrm{~m} \times 4.5 \mathrm{~m}$ black-box room to simulate a setting similar to a theater, re-enacting the scenery of a stage background with reduced lighting. The black box was equipped with two SD square heavy steel truss elements which were fixed on the floor, two tables with tools and components required for truss connection and electric power supply with a busbar. Each truss had a square profile and thus four corners.

The setup of the training session followed industrial training instructions for connecting a truss and included the identification of the items and tools used in the activity and the preparation of one truss element to prepare the connection of another truss element. First, a so-called egg with a conical drilled hole needs to be put correctly into the hole of the longitudinal member at the first edge. Then, a pivot needs to be mounted in the correct direction to fix the egg. For this activity, a hammer is used to ensure a strong connection. The final action is to secure the pivot with a spigot. Figure 4 shows the AR simulation of these steps. All four corners of the truss need to be prepared this way.

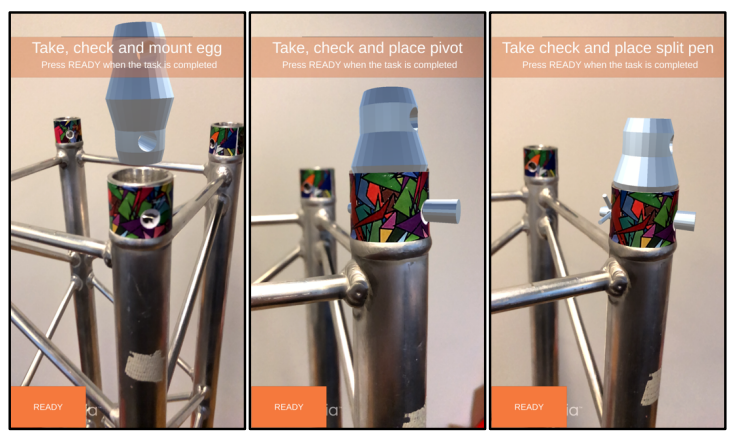

Figure 4. Simulation of connecting parts

In our simulation, we designed the apps following a learning process based on Peyton's four learning steps: demonstration, deconstruction, comprehension, and execution [27]. Using the tablet / smartphone app, trainees need to start the app and point the camera of their device towards the truss. At the first corner, the app superimposes a 3D model of the egg to demonstrate how to install the egg into the hole and the trainee is requested to follow the instructions. To get to the next step, the trainee needs to push a button and the app shows with 3D animations how to correctly put the pin into the holes of the truss. Once the trainee is ready for the next task, the app displays a 3D animation demonstrating how the spigot should be placed

${ }^{1}$ See WEKIT - Wearable Experience for Knowledge Intensive

Training, https://www.wekit.eu 
correctly. During the session, the trainer is invited to give verbal feedback and to intervene, if corrections are necessary. At the end of each step and the activities on the first corner, the trainer is requested by the system to send feedback based on a predefined checklist and starts the training on the second corner. The information provided by the trainer's checklist is stored at the LRS and contain aspects for evaluating a trainee's task performance linked to the checklist item descriptions (Table 1).

At the second corner, the app provides a single 3D animation combining all three steps of the activity in one animation. Again, the trainee is invited to replicate the given visual instructions and afterwards the trainer checks whether the tasks were fulfilled correctly. Again, the trainer is allowed to give verbal instructions and also to reject the evaluation; in this case, the trainee needs to start again with the activities for the current corner.

For the remaining two corners of the truss, the trainee receives the instructions to assemble the corner on his/her own. Since we want to measure the task performance in these two steps, the app requires pressing a button after successfully assembling corner three and four. Thus, the trainees' task performance, i.e. time to completion, can be measured. The training session itself ends with feedback given by the trainer and the app shows the participant's performance analysis via a dashboard, based on the analysis of the recorded users' data from the LRS.

The Hololens application works in a similar way as the tablet / smartphone app for the trainees. At the start of the application the user's position was determined based on a reference point in the room (QR code). The user could then complete the individual steps in the training with the help of a menu. While in the tablet / smartphone application the working steps were shown by means of $3 \mathrm{D}$ animations, these instructions were displayed in the form of short videos in the Hololens.

To measure a participant's overall performance, we focused on three aspects like number of correctly/incorrectly fulfilled tasks, the completion time for corners 3 and 4, and the time taken for the whole training scenario. Furthermore, we prepared a questionnaire to receive a participant's feedback based on closed and open questions.

The questionnaire included questions addressing a participant's impression of the system's usefulness (perceived usefulness), perceived learning, and motivation. The answers were given according to a fivelevel Likert scale (strongly disagree, disagree, neutral, agree, totally agree). Perceived usefulness is defined as "the degree to which a person believes that using a particular system would enhance his or her job performance" [12, p. 320]. Perceived learning describes the degree to which a student observes to obtain knowledge in a particular learning situation [22]. Motivation is considered to be intent and engagement as action; both terms are often used interchangeably [17, 30].

Since our study is of exploratory nature, we used the term motivation as a measure for a learner's interest and engagement in a particular learning activity. In that sense, we address a learner's self-perception on this dimension. We phrased the question Q1 "The App was helpful to fulfill the task." to address perceived usefulness (pu), to address perceived learning ( $\mathrm{pl}$ ) questions Q2-Q4 "With this activity I have learned something.", "I have learned about truss connection.", "I can connect trusses correctly and safely.", and to address motivation (m) the questions Q5-Q8 "The introductory story was motivating.", "The task was simple and understandable.", "It was exciting to experiment with the app.", "The activity was entertaining.". Finally, we also included questions (QU1 to QU10) regarding the system usability scale (SUS) [6].

\section{Implementation}

We conducted the field study at a trade fair for the event technology industry. Visitors of the fair were mostly trained people and experts from the field of event technology, which were asked by research assistants outside the black box room to participate in our field study and were then directed into the black box. Inside the black box, the participants could either use the tablet / smartphone or the Hololens application. Hololens users had to go through a short introduction session first to use the app, especially to practice gesture recognition with the Hololens application. Then the Hololens users could start and run their training on their own. Figure 5 shows a participant during the introduction session and screenshots during the training.

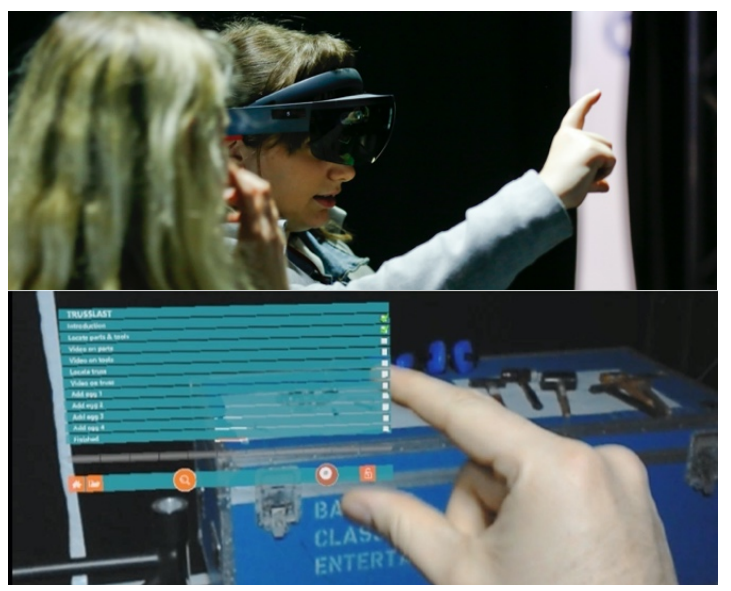

Figure 5. Hololens user in action 
For the tablet/smartphone users, a trainer inside the black box started the training session. At the beginning, Hololens and tablet/smartphone participants were instructed along a storyline: the rigging crew needs help for setting up the stage and is looking for outstanding performers in quick-and-safe-rigging. Thus, the participants first need to successfully complete the training for connecting a truss and to test their skills supported by the new AR training app. The training for Hololens and tablet/smartphone users covered the following activities: in step 1 and 2 participants had to prepare a truss following the instructions to (a) listen to important instructions, (b) correctly identify damaged parts, (c) follow the advices of the physical (tablet/ smartphone) or virtual (Hololens) assessor and the AR animations to connect the parts (egg, pivot, split pen) with the truss, (d) fulfill the tasks in step 3 and 4 on their own, and (e) complete a questionnaire afterwards.

The tablet / smartphone users were accompanied by a human trainer. This trainer handed over an iPad where the training app was already started and connected with the trainer's app. The app provided a unique session code for each training session which was also used as a session identifier and to link sessions and questionnaires. Participants were allowed to ask any questions and the trainer was instructed to support the activities in step 1 and 2 (preparing corner 1 and 2 of the truss). The users had to confirm each step on the tablet/smartphone and the trainer had to confirm this request in the trainer app. Figure 6 shows a participant in action and the interaction with the trainer.

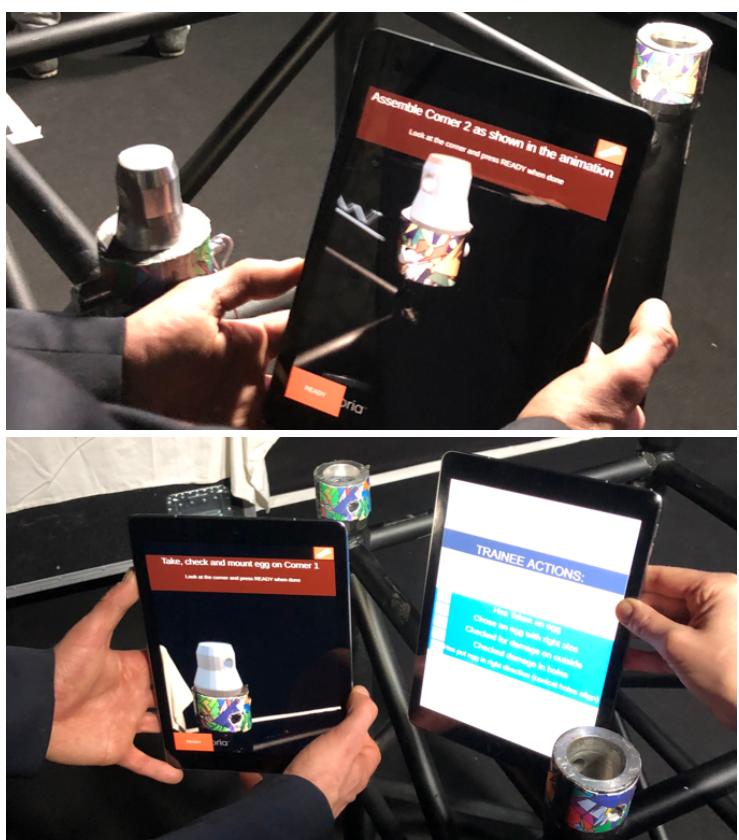

Figure 6. AR on tablet/smartphone app
The Hololens users were guided by the app through the whole training session and had to complete the training sequence similar to the App users (learn about the materials and tools, follow step-by-step instructions). Each training session was identified by an individual session code which was noted on the questionnaire to connect the recorded user data with the given answers after the training session.

\section{Data Analysis}

The training sessions took time between 15 and 45 minutes, including introduction, preparation, training activity, reflection and survey. In our survey, we analyzed the collected data in two ways. The first part covered a manual examination of the participants' qualitative feedback provided in the questionnaire as described in chapter 4 . In the second part, we asked participants closed questions regarding perceived usefulness (Q9: "What do you think are the strengths, benefits?" and Q10: "What do you think are the added values of using the app in such a training scenario?") and perceived learning (Q11: "Introducing AR in trainings, do you think that people learn more and/or faster and/or with higher motivation?"). Finally, we asked for further use cases (Q12: "Which use cases do you think are applicable for implementing AR in workplace training?"). For the data analysis of the second part we applied the innovative synthesis method and a systematic analysis method to support this process, following Whittmore \& Knafl [34].

In a first step, we collected the answers from the questionnaires and assigned them according to design layers like the content layer, mobile layer, motivational layer, and situated/collaborative layer [31]. Hence, we aim to provide the findings from this study for future development, i.e. to contribute to the research field of $\mathrm{AR}$ application design requirements. Furthermore, we counted the given answers to emphasize and quantify the users' perceptions. The analysis shows that most of the participants' answers were given in terms of situated/collaborative learning (73 answers), followed by motivational aspects (72 answers), content-oriented answers (60 answers), and only a few referred to mobile aspects ( 3 answers). Table 2 shows an extract of the collected qualitative feedback.

We continued by analyzing the participants feedback concerning strengths, added value, constraints and use cases, and categorized them. In summary, the most cited positive aspects for introducing interactive and collaborative $\mathrm{AR}$ in workplace trainings were visualization (37), efficiency (29), independence (21), realism (19), process-orientation (17), motivation (15), language independence (13), collaboration (6), and mobile (4) and generic aspects (3). Applicable use cases 
suggested by participants are trainings introducing more complex tasks, safety training, training situations where a trainee have no/low access to tools, and trainings in flexible environments.

Table 2. Feedback aligned with design layers

\begin{tabular}{|c|c|c|}
\hline Layer & Aspects & Quotation \\
\hline \multirow{8}{*}{ 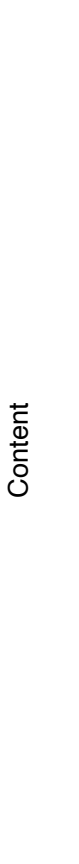 } & language & $\begin{array}{l}\text { Imparts without language barrier } \\
\text { what needs to be done. } \\
\text { Language and nationalities } \\
\text { indepency. }\end{array}$ \\
\hline & descriptive & $\begin{array}{l}\text { The visual representation is very } \\
\text { helpful because it is easy to } \\
\text { understand what needs to be } \\
\text { done. }\end{array}$ \\
\hline & $\begin{array}{c}\text { self- } \\
\text { explaining }\end{array}$ & $\begin{array}{l}\text { Trainer may need to correct only } \\
\text { minor issues and it is self- } \\
\text { explanatory. }\end{array}$ \\
\hline & $\begin{array}{l}\text { under- } \\
\text { standing }\end{array}$ & $\begin{array}{l}\text { The visual, very clear presentation } \\
\text { / instruction makes it easy for } \\
\text { everyone to understand how to } \\
\text { proceed. }\end{array}$ \\
\hline & complexity & $\begin{array}{l}\text { Learning about complex tasks. } \\
\text { Ability to combine a series of } \\
\text { steps. }\end{array}$ \\
\hline & clear & $\begin{array}{l}\text { Intuitive operation and clearly } \\
\text { defined activities. }\end{array}$ \\
\hline & interactive & $\begin{array}{l}\text { Step by step instruction on the } \\
\text { object. }\end{array}$ \\
\hline & multimedia & $\begin{array}{l}\text { Higher memorability through } \\
\text { multisensory learning. }\end{array}$ \\
\hline \multirow{3}{*}{$\frac{0}{\frac{0}{0}}$} & \multirow{3}{*}{ 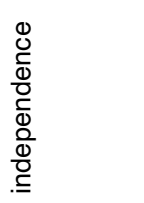 } & $\begin{array}{l}\text { Learning without a trainer, time } \\
\text { and place independent. }\end{array}$ \\
\hline & & $\begin{array}{l}\text { Can be used for several people on } \\
\text { a construction site. }\end{array}$ \\
\hline & & $\begin{array}{l}\text { For trainees and interns as an } \\
\text { exercise in the storage. }\end{array}$ \\
\hline \multirow{7}{*}{ 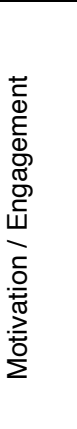 } & simple & simple handling; simple to learn; \\
\hline & quick & $\begin{array}{l}\text { You quickly learn how to handle } \\
\text { the traverse. }\end{array}$ \\
\hline & $\begin{array}{l}\text { enter- } \\
\text { taining }\end{array}$ & $\begin{array}{l}\text { It's quick and entertaining. Hands- } \\
\text { on approach. }\end{array}$ \\
\hline & costs & No need to travel. Cost efficient. \\
\hline & safety & Training with no danger. \\
\hline & pace & $\begin{array}{l}\text { You can train multiple students on } \\
\text { their own tempo. }\end{array}$ \\
\hline & fun & Have fun, enjoy the work. \\
\hline \multirow{3}{*}{ 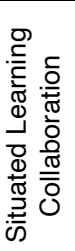 } & $\begin{array}{l}\text { collabo- } \\
\text { rative }\end{array}$ & $\begin{array}{l}\text { You learn together and make no } \\
\text { mistakes. }\end{array}$ \\
\hline & complexity & $\begin{array}{l}\text { Learning about complex tasks. } \\
\text { Ability to combine a series of } \\
\text { steps. }\end{array}$ \\
\hline & realistic & $\begin{array}{l}\text { Realistic, simple and descriptive } \\
\text { training. }\end{array}$ \\
\hline
\end{tabular}

The second step covered the statistical analysis of the quantitative answers of the questionnaire in combination with the user data logged by the system. First, we evaluated the results for Q1, perceived usefulness (pu) with $\mathrm{N}=101$, $\min =1$, $\max =5$, mean $=4.2$ (mean_Hololens $=4.35, \quad$ mean_Tablet $=4.11$, no significant difference). For perceived learning ( $\mathrm{pl}$ ) we aggregated the answers of questions Q2-Q4 with $\mathrm{N}=116$, $\min =1, \max =5$, mean=3.68 (3.79/3.59, no significant difference) and for motivation/engagement (m) we aggregated the answers of questions Q5-Q8 with $\mathrm{N}=123$, $\min =1, \max =5$, mean=4.15 (4.32/4.02, no significant difference). In addition, we calculated the SUS for each participant to learn how participants perceived the usability of the AR apps. The mean value in our evaluation was $70.02(67.84 / 71.78)$, which is comparable with SUS values of good products [6]. In this evaluation, it was still noticeable that the Hololensusers were significantly more uncertain about system usability in regards to questions QU4 „I think that I would need the support of a technical person to be able to use this system.“ and QU10 „I needed to learn a lot of things before I could get going with this system." and in comparison with the tablet/smartphone-users.
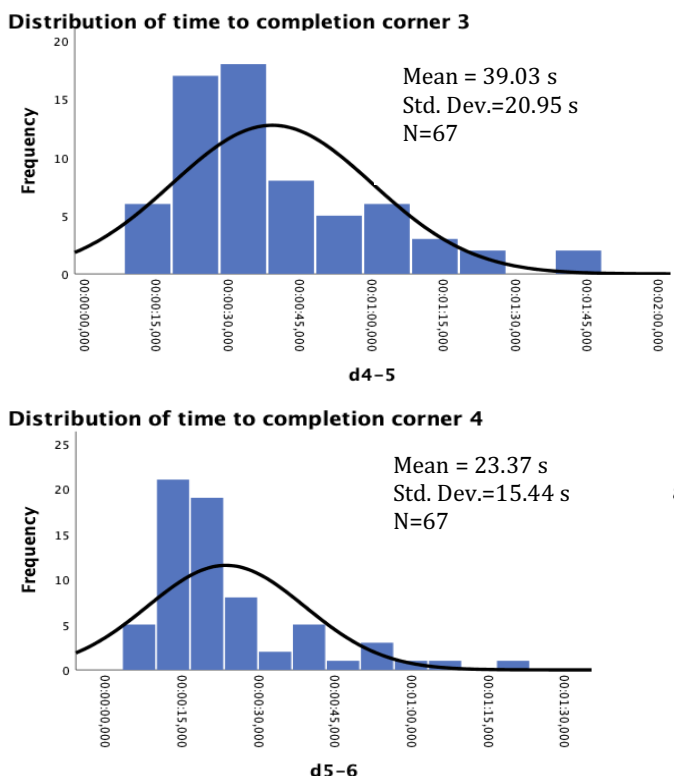

Figure 7. Histogram time to completion corner 3, 4

Furthermore, we analyzed the user data collected by the tablet / smartphone AR app and investigated metrics like task performance regarding the overall training process (d0-6), and especially for the completion of the tasks in corner $3(\mathrm{~d} 4-5)$ and $4(\mathrm{~d} 5-6)$ of the truss preparation activity. This was only possible for this application, as the trainer could monitor the activity 
during the session and control the correct execution. Figure 7 shows a visual representation of the data.

We conducted a paired t-test to compare the time to completion for corner 3 and 4 . There was a significant difference in the scores for time to completion of corner $3(\mathrm{M}=39.03, \mathrm{SD}=20.95)$ and corner $4(\mathrm{M}=23.37$, $\mathrm{SD}=15.44)$, with $\mathrm{t}(66)=5.707, \mathrm{p}<0.001)$. These results suggest that participants were faster at corner 4 than corner 3.

For the quantitative evaluation of the questionnaires we focused on perceived usefulness and perceived learning and the questions whether participants learned more, faster, and with higher motivation. The first investigation addresses the interdependence between perceived usefulness (pu) and the SUS (uscore). The results show a significant and strong correlation $(\mathrm{r}=0.599, \mathrm{n}=101, \mathrm{p}=0.000)$ between $\mathrm{pu}($ mean $=4.2)$ and uscore (mean=70.02). This suggests that participants who valued the app as helpful assessed its usability on a higher level, or participants who uprated the system's usability perceived the app as helpful. In terms of perceived usefulness and motivation $(\mathrm{m}$, mean $=4.20)$ in the training session, we found a medium positive correlation between those variables $(r=0.468, n=96$, $\mathrm{p}=0.000$ ). This indicates that participants who found the app helpful to fulfill the task were also more motivated.

Investigating the correlation between perceived usefulness and perceived learning $(\mathrm{pl}$, mean $=3.74)$, we found a medium positive correlation $(\mathrm{r}=0.376, \mathrm{n}=90$, $\mathrm{p}=0.003$ ). This suggest that participants who found the app helpful to fulfill the task also perceived that they have learned more. Alternatively, participants who perceived that they have learned more found the app more helpful.

In addition, we rated the answers for Q3 (“... people learn more / faster / with higher motivation with AR in trainings") from our qualitative feedback section of the questionnaire and awarded 2 points for a clear and positive answer (yes), 1 point for a positive answer with reservations, 0 points for an unbiased answer, -1 point for a negative answer with restrictions and -2 points for a clear and negative answer (no). In this way we calculated and defined a variable as "learnvalue" for the whole participant group with $\mathrm{N}=98$ and mean=1.1 (Hololens: $\mathrm{N}=39$, mean=1.23; Tablet: $\mathrm{N}=59$, mean=1.02).

Examining the value interpreted from participants' qualitative feedback in regards to learning, the computed Pearson correlation coefficient showed a medium positive correlation between perceived usefulness and the examined learn-value $(r=0.402$, $\mathrm{n}=57, \mathrm{p}=0.002$ ). Participants who agreed that the app is useful also valued the effectiveness of AR in trainings with higher approval.
Since motivation was an aspect addressed in Q3 of the questionnaire too, we also tested if a correlation between the variables ( $\mathrm{m}$ and learnvalue) is verifiable. The calculated Pearson coefficient shows a strong positive correlation $(\mathrm{r}=0.633, \mathrm{n}=57, \mathrm{p}=0.000)$ which indicates that participants with higher motivation felt more confident about AR's effectivity.

\section{Discussion and Conclusion}

Our findings from the field study provide considerable insights for the implementation of interactive and collaborative $\mathrm{AR}$ in a workplace training, especially in terms of trainees' motivation, excitement and engagement. We could confirm the effect of AR applications in educational settings for usability and motivation, especially in terms of student engagement and satisfaction as shown in similar studies $[4,20,29]$. The methodology foundation in DSR supported the entire process, i.e. aligning and advancing the AR development by implementing a node editor tool to adapt the AR prototypes to the project's requirements.

To answer our research question, what benefits and added value do users see in using interactive $A R$ in workplace training, our study revealed a number of positive aspects reported by participants. Users commented positively on the use of AR for training purposes due to the benefits of clear visualization, a guided and step-by-step learning, various aspects of higher efficiency, independence of time and frequency, and the combination of the virtual and real world to provide a realistic training. Especially the users of the tablet/smartphone app have positively evaluated the aspect of cooperation with a trainer in such a training environment.

Our study was driven by the assumption that VET trainees using AR based learning systems learn with a higher motivation and achieve a fast, measurable learning outcome. The results of the qualitative and quantitative analysis confirm this assumption. Moreover, we found that participants with higher motivation felt more confident about AR's effectivity and participants who found the app helpful to fulfill the task also perceived that they have learned more. In particular, we were able to show that participants who found the app helpful to fulfill the task were also more motivated. Participants also improved their learning results over the training session and were faster at corner 4 than corner 3.

Especially in terms of the received feedback from subject matter experts and the evaluation of the targeted variables, i.e. usability, perceived usefulness, perceived motivation, and perceived learning, interactive and collaborative AR was largely approved by the participants. We successfully implemented a process- 
oriented set of instructions in our AR app development, which was aligned with the requirements derived from a standardized training curriculum from industry, and introduced features for collaboration in the given setup. That way, we were able to demonstrate the application of interactive $\mathrm{AR}$ in a workplace training and provide details for the AR design framework in return. Since trainers and trainees benefitted from the motivational, interactive, collaborative and realistic training setting and appreciated aspects derived from the design, e.g. the interactive, intuitive and safe application, we identified independency, efficiency, and process-orientation as added value of $A R$ in workplace trainings.

However, with the results of the field study we could confirm Billinghurst stating that process and subjective measures may be more important than quantitative outcome measures in AR experiments $[5, \mathrm{p}$. 198]. Mainly in terms of interaction and collaboration and the applied step-by-step approach in the training, experts mentioned that interactive and collaborative AR opens up new opportunities to structure trainings individually, e.g. to first let trainees interact with the environment to overcome a trainee's inhibitions and in a second step, discuss training aspects in detail. Some experts argued in the direction that particularly in the first training sequence the trainer should add fundamental details to supply the trainee with important information. That way collaboration in trainings supports individual learning paths.

We did not aim to run a comparison between the Hololens app and the tablet/smartphone app. Our evaluation did not show any significant difference in the results from the evaluation of the participants questionnaires, except the fact that the Hololens-users had to learn about the use of the system and needed more support compared to the tablet/smartphone-users.

We noticed from our own observation and the participants' feedback that the task performance was slowed due to the AR application, similar to other studies $[25,29]$ and mostly because of usability issues. Especially in the first consecution of the training, participants required to get used to the system, i.e. pointing the camera in a good angle to the trigger image and starting the AR visualization, or had to get used to handling the Hololens first.

Since we focused our research on receiving qualitative and expert feedback, we utilized age and gender issues to a lesser extent, or did not consider the educational background of the individual participants. In terms of gender we could identify that 24 female and 103 male participants took part in our field study. This distribution reflects the gender situation of the industry (higher number of male employees) and therefore the strong male dominance in the professional field of event technology. However, we could not find any meaningful evidence for gender related differences for our study which could be caused by the small group of female participants in our field study. On the other hand, this finding could serve as representation for the equal skills between men and women in the particular industry.

We have not recorded the training situations on video to identify any differences in the individual training sessions. Since we worked with different trainers during the field study, this situation could have possibly influenced the results. Although we instructed the involved staff according to the structured process for the field study, personal aspects could have influenced participants' motivation and behavior in the training session (e.g. sympathy, level of details explained). However, an analysis towards differences in the collected data considering session dates and times did not show any effect.

Many participants noted that the task was too simple and referred to more complex tasks which would be interesting to investigate the application of collaborative AR at workplaces. Thus, the task simplicity could have had an influence on a participant's motivation and the perceived aspects like learning and usefulness in our study. However, we prepared the app in a way that makes it possible to map more complex tasks, which we intend to implement in our further research

In contrast to this work, very few user studies report on interactive and collaborative AR for workplace training and almost none that examined communication process measures. Since communication is a key aspect in interactive and collaborative training environments, future research should investigate in how active collaboration can be explored and how collaborative AR applications can be designed and implemented to support communication processes and their measuring. One of our next steps will be to evaluate the AR app in contrast to traditional trainings in a control-group design. We are currently working on an AR training simulation for a series of workplace trainings where the truss app is one training scenario and which refers to a definite skills-set, thus leads to a qualification for stage technicians based on industry standards.

\section{References}

[1] L. A. Adams and J. F. Courtney, "Achieving relevance in IS research via the DAGS framework", Proceedings of the 37th Annual Hawaii International Conference on System Sciences, 2004, pp. 1-10.

[2] S. Adams Becker, M. Cummins, A. Davis, A. Freeman, C. Hall Giesinger and V. Ananthanarayanan, "NMC Horizon Report: 2017 Higher Education Edition", Austin, Texas: The New Media Consortium, 2017.

[3] M. Akçayır and G. Akçayır, "Advantages and challenges associated with augmented reality for education: A 
systematic review of the literature", Educational Research Review, 20, 2017, pp. 1-11.

[4] J. Bacca, S. Baldiris, R. Fabregat, \& S. Graf, "Mobile Augmented Reality in vocational education and training", Procedia Computer Science, 2014, pp. 49-58.

[5] J. Bacca, S. Baldiris, R. Fabregat, \& S. Graf, "Augmented reality trends in education: a systematic review of research and applications", Journal of Educational Technology \& Society, 17(4), 2014, pp. 133.

[6] A. Bangor, P. T. Kortum and J. T. Miller, „An empirical evaluation of the system usability scale", Intl. Journal of Human-Computer Interaction, 24(6), 2008, pp. 574-594.

[7] M. Billinghurst, S. Weghorst and T. Furness, "Shared space: Collaborative augmented reality", In Proceedings of CVE' 96 Workshop, 1996.

[8] M. Billinghurst, S. Weghorst and T. Furness, "Wearable computers for three dimensional cscw", In 2012 16th International Symposium on Wearable Computers, IEEE Computer Society, 1997, pp. 39-39.

[9] M. Billinghurst and Hirokazu Kato. "Out and about - real world teleconferencing”, BT technology journal, 18(1), 2000, pp. 80-82.

[10] M. Billinghurst, A. Clark and G. Lee, "A survey of augmented reality". Foundations and Trends ${ }^{\circledR}$ in Human-Computer Interaction, 8(2-3), 2015, pp. 73-272.

[11] J. Cabero Almenara and J. Barroso, "The educational possibilities of Augmented Reality", In New Approaches in Educational Research 5(1), 2016, pp. 44-50.

[12] F. D. Davis, "Perceived usefulness, perceived ease of use, and user acceptance of information technology", In MIS quarterly, 1989, pp. 319-340.

[13] P. Dillenbourg, "Over-scripting CSCL: The risks of blending collaborative learning with instructional design", Heerlen, OpenUniversiteit Nederland, 2002, pp.61-91.

[14] A. Dünser, R. Grasset and M. Billinghurst, "A survey of evaluation techniques used in augmented reality studies", Human Interface Techn. Lab New Zealand, 2008, pp. 5.

[15] M. Dunleavy, C. Dede and R. Mitchell, "Affordances and limitations of immersive participatory augmented reality simulations for teaching and learning", Journal of science Education and Technology, 18(1), 2009, pp. 7-22.

[16] T. Elias, "Learning analytics", Learning, 2011, pp. 1-22.

[17] J. Fredricks, W. McColskey, J. Meli, J. Mordica, B. Montrosse and K. Mooney, "Measuring Student Engagement in Upper Elementary through High School: A Description of 21 Instruments", Issues \& Answers, REL 2011-No. 098, Regional Educational Laboratory Southeast, 2011

[18] V. Havard, D. Baudry, A. Louis and B. Mazari, "Augmented reality maintenance demonstrator and associated modelling", in: 2015 IEEE Virtual Reality Conference, VR 2015 - Proceedings, 2015, pp. 329-330.

[19] D. Helgason, N. Francis and J. Ante, "Unity3D", Copenhagen: Unity Technologies, 2004.

[20] J. Jetter, J. Eimecke and A. Rese, „Augmented reality tools for industrial applications: What are potential key performance indicators and who benefits?". Computers in Human Behavior, 87, 2018, pp. 18-33.
[21] J. M. Kevan and P. R. Ryan, "Experience API: Flexible, decentralized and activity-centric data Collection". Technology, Knowledge Learning, 21(1), 2016, pp. 143-149.

[22] A. J. Martin, "Examining a multidimensional model of student motivation and engagement using a construct validation approach", British Journal of Educational Psychology, 77(2), 2007, pp. 413-440.

[23] A. Meyer, D. Rose D and D. Gordon, "Universal Design for Learning, theory and practice" Wakefield, MA: CAST Professional Publishing, 2014.

[24] J. F. Jr. Nunamaker, M. Chen and T.D. Purdin, "Systems Development in Information Systems Research," Journal of Management Information Systems, 1991, pp. 251-266.

[25] R. Palmarini, J. A. Erkoyuncu, R. Roy, R. and H. Torabmostaedi, "A systematic review of augmented reality applications in maintenance", Robotics and Computer-Integrated Manufacturing, 49, 2018, pp. 215228.

[26] K. Peffers, T. Tuunanen, C. E. Gengler, et al., „The Design Science research process: a model for producing and presenting information systems research", Proc. of the First Int. Conference on Design Science Research in Information Systems and Technology (DESRIST 2006), 2006, pp. 83-106.

[27] J. W. R. Peyton, "Teaching in theatre. Teaching and learning in medical practice”, Manticore, 1998, pp. 171180.

[28] I. Radu, "Why should my students use AR? A comparative review of the educational impacts of augmented-reality", In 2012 IEEE International Symposium on Mixed and Augmented Reality (ISMAR), 2012, pp. 313-314.

[29] I. Radu, "Augmented reality in education: a meta-review and cross-media analysis", Personal and Ubiquitous Computing, 18(6), 2014, pp. 1533-1543.

[30] A. L. Reschly and S. L. Christenson, "Jingle, jangle, and conceptual haziness: Evolution and future directions of the engagement construct", In Handbook of research on student engagement, Springer, Boston, 2012, pp. 3-19.

[31] P. Sommerauer and O. Müller, "Augmented Reality for Teaching and Learning - a Literature Review on Theoretical and Empirical Foundations", Proceedings of the 26th European Conference on Information Systems (ECIS), Portsmouth, UK, 2018.

[32] J. E. Swan and J. L. Gabbard, "Survey of user-based experimentation in augmented reality", Proccedings of 1st Int. Conference on Virtual Reality (22), 2005, pp. 19.

[33] Z. Szalavári, D. Schmalstieg, A. Fuhrmann and M. Gervautz, "Studierstube: An environment for collaboration in augmented reality. Virtual Reality, 3(1), 1998, pp. 37-48.

[34] R. Whittemore and K. Knafl, "The integrative review: updated methodology", Journal of advanced nursing, 52(5), 2005, pp. 546-553.

[35] D. W. Van Krevelen and R. Poelman, "A survey of augmented reality technologies, applications and limitations", International journal of virtual reality, 9(2), 1,2010 . 